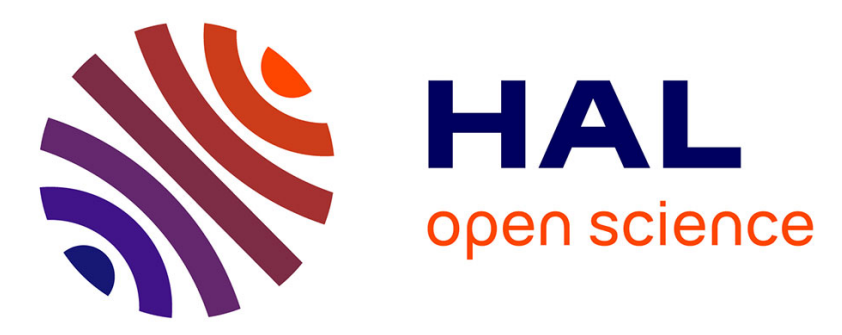

\title{
FIELD-INDUCED IONIZATION AND EMISSION OF ELECTRONS AND IONS IN MIS STRUCTURES
}

\author{
V. Litovchenko, I. Lisovskii
}

\section{To cite this version:}

V. Litovchenko, I. Lisovskii. FIELD-INDUCED IONIZATION AND EMISSION OF ELECTRONS AND IONS IN MIS STRUCTURES. Journal de Physique Colloques, 1988, 49 (C6), pp.C6-137-C6-143. 10.1051/jphyscol:1988623 . jpa-00228120

\section{HAL Id: jpa-00228120 https://hal.science/jpa-00228120}

Submitted on 1 Jan 1988

HAL is a multi-disciplinary open access archive for the deposit and dissemination of scientific research documents, whether they are published or not. The documents may come from teaching and research institutions in France or abroad, or from public or private research centers.
L'archive ouverte pluridisciplinaire HAL, est destinée au dépôt et à la diffusion de documents scientifiques de niveau recherche, publiés ou non, émanant des établissements d'enseignement et de recherche français ou étrangers, des laboratoires publics ou privés. 


\section{FIELD-INDUCED IONIZATION AND EMISSION OF ELECTRONS AND IONS IN MIS} STRUCTURES

\section{V.G. LITOVCHENKO and I.P. LISOVSKII}

Institute of semiconductors, Academy of Sciences of the Ukrainian S.S.R., Kiev (U.S.S.R.) 252028, Kiev-28, Prospect Nauki 45, U.S.S.R.

Abstract - The effects of field emission and field-induced defect creation in MIS structures with modified insulator layers were investigated. It was found that in this case the processes involved possessed a number of specific features. The experimental data permit one to calculate the parameters of field emission for modified and graded insulator structures. New effects of fast and slow surface state created at the $\mathrm{Si}-\mathrm{SiO}_{2}$ interface, caused by positive bias were observed, A model based on field emission of protons is proposed.

\section{1 - INTRODUCTION}

The main features of phenomena such as field ionization (FI) and emission (FE) in a metal-insulator-semiconductor (MIS) layer system are determined by its multiphase structure, where the role of vacuum is played to some extent by an insulator. Here, high electric fields can be formed both near the external (metal-insulator [MI]) and internal (insulator-semiconductor [IS]) interfaces. This leads, under certain conditions, to the appearance of electron or ion field emission into the insulator $/ 1,2 \%$. The electron field emission in MIS structures has been studied rather extensively in recent years/2-4/. The schemes of it are shown in Fig. 1.

The behavior of emission currents and the defect creation processes (mainly in the insulator) caused by emitted carriers have been investigated within a wide range of electric fields and temperatures. In basic microelectronic $\mathrm{M}-\mathrm{SiO}_{2}$-Si sysstems the field emission of carriers was observed at high fields $(-3-5 \mathrm{MV} / \mathrm{cm})$ and was found to be mainly the emission of electrons determined by the Fowler-Nordheim tunneling. In some specific MIS structures (e.g., $\mathrm{Si}_{3} \mathrm{~N}_{4}$ systems with electrolytic gate electrode, etc.) the hole emission is also important. The degradation of insulator parameters was observed at high densities of the injected electron charge/2,3/. This work considered ordinary MIS structures having standard $\mathrm{SiO}_{2}$ layer as an insulator.

At the same time, the use of modified insulator layers seems to be promising for the control of the field emission processes in such MIS structures. In particular, the electric field enhancement in the insulator and IS or IM interfaces, the lowering of the effective emitting barrier must result in a remarkable increase of field emission. Besides, the formation of strong local fields in the insulator layer may lead to the field-stimulated creation of defects. In the present work the following modifications of the insulator providing these effects were chosen: (1) charging of the insulating layer; (2) the creation of the insulating layer; (3) the use of graded energy band gap insulator (GEBI). The results of these investigations are presented below.

\section{2 - EXPERIMENTAL TECHNIOUE}

The following 3 groups of silicon MIS structures were used.

1. Usual $\mathrm{M}-\mathrm{SiO}_{2}-\mathrm{Si}$ structures subjected to an additional treatment that caused a large negative charge built into the dielectric.

2. Usual MIS structures which together with the built in charges contain high density of slow states.

3. Structures with a graded energy band gap insulator.

The samples of group 1 were prepared as follows: n-type si was oxidized in water vapor up a thickness of $240 \mathrm{~nm}$. Semitransparent NiCr electrodes were deposited on the $\mathrm{SiO}_{2}$ surface. The negative charge distributed within the oxide layer was obtained by UV irradiation under bias. Low irradiation doses or irradiation at liquid nitrogen temperature stimulated only the appearance of high density negative charge in the oxide but without SS (Fig. 2). 
The samples of group 2 were obtained by high dose UV irradiation of MIS structures at room temperature.

In case 3 , the 1-3 nm thick $\mathrm{SiO}_{2}$ layer was grown on $S i$ surface, on top of which a $80 \mathrm{~nm}$ thick $\mathrm{Si}_{\mathrm{x}} \mathrm{O}_{\mathrm{y}} \mathrm{N}_{\mathrm{z}}$ film was deposited pyrolytically. The parameters $\mathrm{X}, \mathrm{Y}$, and $\mathrm{Z}$ were determined during the synthesis process and could be constant or varying over the insulator thickness/4/. Aluminum field electrodes were deposited on the insulator surface.

Capacitance-, dark current-, and photocurrent-voltage dependencies $C(V), I(V)$ and $I_{p}(V)$ were measured. From high frequency $C(V)$ curves the value of flat band voltage $\left(V_{\mathrm{FB}}\right)$ or the sum of interface $\left(Q_{i t}\right)$ and oxide $\left(Q_{o t}\right)$ charge densities as well as fast surface states spectra $\mathrm{N}_{t}\left(\mathrm{U}_{S}\right)$ were calculated. The photoinjection technique allowed the determination of the oxide charge density/5/. Using the electron and hole emission dark currents, the centroids of the negative $\left(\mathrm{X}_{e}\right)$ and positive $\left(\mathrm{X}_{\mathrm{h}}\right)$ charges in the graded insulator were determined $/ 6 /$.

\section{3 - INTERNAL FIELD EMISSION OF ATOMIC PARTICLES (PROTONS)}

If an MIS structure is subjected to WV irradiation for a rather short time, a uniform negative charge up to $10^{17} \mathrm{~cm}^{-3}$ is accumulated over the oxide layer. However, the defect density at the interface does not increase considerably/7/. A subsequent prolonged field treatment at $v_{G}>0$ leads to a substantial increase in the fast surface state density at the IS interface and to the appearance of a high density positively charged traps in the oxide near the Is interface. These effects are illustrated in Figs. 3 and 4.

It is seen from Fig. 4 that the value of $Q_{o t}+Q_{i t}$ is effectively reduced as a result of field treatment with the rate depending both on the value of $v_{G}$ and the oxide negative charge density. A comparison of $C(V)$ curves with photoinjection $I_{p}(V)$ dependencies has shown that the relaxation is only partially associated with a reduction of negative charge in the oxide, because simultaneously a positive "field induced" charge is accumulated at $\mathrm{Si}^{-\mathrm{SiO}_{2}}$ interface.

This effect is observed only after the application of a positive bias in distinction with well-known effects of "negative-bias instability" $/ 8$. The treatment of the structure at liquid nitrogen temperature or the initial structures (without distributed negative charge) did not lead to this phenomena. All these peculiarities (i.e., positive bias, temperature dependance, long times of the processes, appearance of positive charge simultaneously with annealing of a part of negative charge) can be explained using the assumption of slow drift through the oxide of a positively charged atomic particle having rather high mobility towards the $\mathrm{Si}_{-} \mathrm{SiO}_{2}$ interface. The escape of electrons from the existing traps or hole participation must be excluded because of the absence of the effect considered at $\mathrm{V}_{\mathrm{G}}<0$.

When studying earlier the processes responsible for the creation of the so-called S-II fast surface states characterized by a peak of density near the mid-gap of Si, we proposed a model of an electrochemical multistage reaction with the participation of atomic hydrogen $/ 7,9 \%$. Final defect of such a reaction is $\mathrm{Si}^{3+}$ center. Direct SIMS experiments have also shown an increase of hydrogen concentration near the $\mathrm{Si}_{-}-\mathrm{SiO}_{2}$ interface after the injection of electrons/10\%. Appearance of trivalent silicon after the injection was also detected with the help of EPR/11/. The model of positive charge creation in $\mathrm{SiO}_{2}$ due to hot electron injection deals with some particles, hydrogen atom being one of them $/ 2 /$. An injection of free hydrogen into the oxide from the external interface was observed earlier using thermopolarization technique/12/, however, at higher $\left(250^{\circ} \mathrm{C}\right)$ temperatures. In the presented work both the creation of the positive oxide charge and the fast surface states coinciding in parameters with those of S-II was observed.

The facts listed above allow to conclude that the positively charged particle participating in the creation of the defects observed after high-field treatment is a proton $\left(\mathrm{H}^{+}\right)$. Its release at room temperature is caused by high electric fields at the anode (at the metal contact) at the expense of space distributed negative charge in the oxide and external bias. In this case the field at anode is $/ 2 /: \mathrm{E}^{\mathrm{a}}=$ $\mathrm{v}_{\mathrm{G}} / \mathrm{d}_{\mathrm{O}}+\mathrm{eQ}_{\mathrm{ot}} / \epsilon_{\mathrm{o}}$. The second term causes an increase in field strength with respect to that in the uncharged insulator by the factor of 1.5 to 2 . This can result in the breaking of the hydrogen bonds in hydrogen-containing complexes at metal-oxide interface and a subsequent drift of the released protons, i.e., to the emission of protons into the oxide according to field enhanced mechanism. A scheme of the proposed process is presented in Fig. 2, and the corresponding reactions are: 
(1) $\mathrm{A}-\mathrm{H}+\mathrm{h} \rightarrow \mathrm{A}^{\circ}+\mathrm{H}^{+} \quad$ (at $\mathrm{M}-\mathrm{SiO}_{2}$ interface),

(2) $\mathrm{Si}-\mathrm{H}+\mathrm{H}^{+} \rightarrow \mathrm{Si}^{3+}+\mathrm{H}_{2}$ (near and at $\mathrm{Si}-\mathrm{SiO}_{2}$ ).

Here the reaction (1) describes the field emission of protons after breaking the bonds between hydrogen and radical (A) in a hydrogen-containing complex and the removal of electron form A-H bond into the metal. The reaction (2) reflects hydrogen (proton) interaction with the weakened bonds in the region at and near $\mathrm{Si}_{-} \mathrm{SiO}_{2}$ interface, where the final product $\mathrm{Si}^{3+}$ plays the role of a donor FS or positively charged center in the oxide.

Taking into account that the rate of the reaction (2) cannot. influence the accumulation rate of the positive charge near the $\mathrm{Si}_{-\mathrm{SiO}_{2}}$ interface and assuming that protons drift through the oxide is sufficiently fast $\left(\tau_{\mathrm{H}^{+}} \approx 1-10^{2} \mathrm{~s}\right)$ one can conclude that the limiting stage is the emission of protons. We evaluated the rate of positive charge accumulation in the oxide (from the results, of Fig. 4) and the value of the anodic fleld for the corresponding relaxation dependance has been calculated. As the result in $(\mathrm{dQ} / \mathrm{d} t)$ versus $\sqrt{\mathrm{E}^{a}}$ dependance has been obtained (see insert in $\mathrm{Fig}$. 4). The experimental points coincide reasonably with a straight line, indications that field emission of protons is described. by the Poole-Frenkel law: dQ/dt $\mathrm{E}^{\mathrm{a}} \exp$ [2a $\sqrt{E^{a}} / \mathrm{kT}$ ], where $\mathrm{a}-2 \sqrt{\mathrm{e} / 4 \pi \epsilon \epsilon} / 1 /$. The parameter a for $\mathrm{SiO}_{2}$ was calculated and gave a value of $2 \times 10^{-4} \mathrm{c} \cdot \mathrm{v}^{1 / 2} \mathrm{~cm} 192$. The experimental value of a determined from Fig. 4 was $-3 \times 10^{-4} \mathrm{C} . \mathrm{v}^{1 / 2} \mathrm{~cm}^{1 / 2}$. This agreement provides additional proof for the validity of Poole-Frenkel emission of protons in our case.

\section{4 - FIELD EMISSION OF ELECTRONS FROM THE SEMICONDUCTOR INTO THE INSULATOR AND BACK}

High dose UV irradiation of biased MIS structures leads to the creation of the built-in positively charged slow states localized near the Is-interface (samples of the group 2). These slow states are capable of taking part in the charge exchange with the semiconductor surface provided sufficiently high electric field exists in the given region. SS discharging and charging processes in the case of anodic $\left(V_{G}>0\right)$ and cathodic $\left(V_{G}<0\right)$ field treatment were investigated. The charge state changes for short periods of time (minutes). The rates depend on the value of $v_{G}$ increasing sharply with its growth. Two features of the processes' considered seem to be of principle. The emission of electrons from semiconductors cannot completely eliminate the positive charge accumulated on SS regardless of the value and duration of the applied field. The annilation of the charge finished when its value achieved one and the same level of $8 \times 10^{11} \mathrm{~cm}^{-2}$. Secondly, the emission processes on and from ss are characterized by essentially different efficiency: the treatment at $-40 \mathrm{~V}$ during 1 hour led to increase

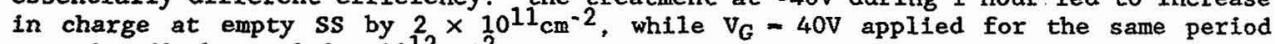
caused a discharge $1.2 \times 10^{12} \mathrm{~cm}^{-2}$ centers.

The regularities described can be qualitatively explained within the framework of the following model (Fig. 5). The induced SS have energies within the range of those for fast states (FS) and are localized at a tunnel distance from silicon. When positive bias is applied, the silicon surface is enhanced with the electrons and the major part of FS is filled. If the electric field is large enough for tunneling, an electron transfers from FS onto SS and neutralized it (Fig. 5,1). The level of the empty SS is shifted due to polarization of the $\mathrm{SiO}_{2}$ medium down into the energy range corresponding to valance-band of silicon (Fig. 5,2 ). When in such a situation a negative bias is applied, the electrons cannot leave the neutral ss because almost all the levels in V-band of $S i$ are filled. Only a small upper part in the SS energy spectrum can emit electrons into the inversion layer of $\mathrm{si}(\mathrm{Fig}, 5,3)$.

\section{5 - FIELD EMISSION OF ELECTRONS AND HOLES IN MIS STRUCTURES WITH A GRADED INSULATOR}

The graded energy band gap may substantially affect the characteristics of field emission $/ 4 /$. The changes in flat-band voltage $\Delta V_{F B}$ were measured during accumulation of positive $Q_{h}$ and negative $Q_{e}$ charges in the insulator at various values of the electric field in the homogeneous part of the insulator. The centroids for such samples $X_{e}, H_{h}$ were found to be shifted substantially towards the IS interface more than for a control homogeneous MNOS structure, Fig. 6. This is associated with a considerable growth of the potential barriers for the carriers injected from silicon.

The potential barrier created in the second insulator prevents from the penetration of the carriers injected from $S i$ to the gate electrode. This, in turn, reduces the depth of the accumulated charge centroid and, hence increases the value of $\Delta V_{F B}$.

Field dependencies $\Delta V_{\mathrm{FB}}$ for the positively biased MNOS structure are shown in Fig. 6. As $E_{G I}$ rises, the curve 1 in Fig. 6 achieves a maximum, which proves the compensating influence of holes injected for the gate electrode into insulator. In the case of graded insulator MIS structures this effect is absent, since the potential barriers existing in this case at the MI-interface prevent from the carriers injection from the metal. 
Taking into consideration the effect of current transport and expressions for $E(X)$ and $V(X) / 1,4 /$ we obtained a formula for calculation of the charge tunneling coefficient, $D_{G I}$, for the barrier created by the graded insulator and metal,

$D_{G I}=D_{0}\left\{\exp -\frac{2}{h} \int_{0}^{X_{t}}(2 m *)^{1 / 2}\left[\Phi_{M}-\left(e E_{G I}+e \beta d_{G I}\right) x+\frac{1}{2} e \beta x^{2}\right] 1 / 2\right\} d x$,

where

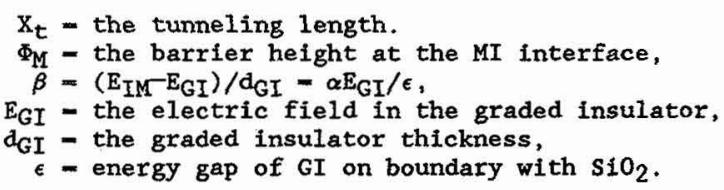

The dependencies $D\left(E_{\mathrm{GI}}\right)$ calculated from this formula are shown in Fig. 6 . It is seen in Fig. 6,2 that the tunneling probability of carriers (holds) from aluminum electrode through the barrier created by graded insulator is considerably lower than in MNOS structures. The use of another type of graded structure $(\beta<0)$ with decreasing inner field from the metal contact leads to a substantial increase in the barrier transparency, which may provide an effective injection of carriers from the metal electrode in the region of relatively weak field $\mathrm{E}_{\mathrm{GI}}$.

The dependencies $D\left(E_{G I}\right)$ obtained are used for the calculation of $\Delta V_{F B}\left(E_{G I}\right)$ curve. Since in the region of small values of $\mathrm{E}_{\mathrm{GI}}$ the carrier tunneling probability from the metal electrode is negligible the changes both in MNOs and in graded insulator MIS structures take place at the expense of the "-" charge injected from $S i$, and the dependencies $\Delta \mathrm{V}_{\mathrm{FB}}\left(\mathrm{E}_{\mathrm{GI}}\right)$. for different samples coincide (Fig. 6). The discrepancy between the curves 1 and 3 at $\mathrm{E}_{G I}>5.5 \times 10^{6} \mathrm{~V} / \mathrm{cm}$ is caused by the Fowler-Norheim emission of holes from the gate electrode. For its quantitative evaluation the meaning of $\Delta V_{F B}$ for given $E_{G I}$ must be decreased by the value:

$$
\Delta \mathrm{V}_{\mathrm{FB}}=\Delta \mathrm{Q}_{\mathrm{FN}} \mathrm{X}_{t} / \epsilon \epsilon_{o}-\mathrm{C}_{\mathrm{FN}} \mathrm{E}_{\mathrm{BI}} \mathrm{D}_{\mathrm{GI}} r \mathrm{X}_{t} / \epsilon \epsilon_{0}
$$

where

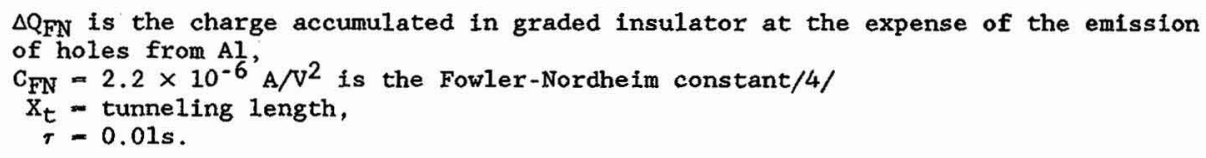

To calculate $\Delta V_{F B}$ we have chosen $m_{G I}^{*}=0.21 \mathrm{~m}_{e}$, which is an average between effective masses for $\mathrm{SiO}_{2}(0.28 \mathrm{~m})$ and $\mathrm{Si}_{3} \mathrm{~N}_{4}(0.114 \mathrm{~m} e)$. As a result we obtain curve 4 in Fig. 6 which is in good agreement with experimental curve 1 up to $E_{G I} \approx 7.5 \times 10^{6} \mathrm{~V} / \mathrm{cm}$.

\section{GONCLUSIONS}

The field-stimulated processes in MIS structures with modified insulators possess a number of features. High positive bias applied to the gate electrode of an MIS structure results in the appearance of a positive oxide charge as well as donor fast surface states. A model of field emission of protons from the external region of $\mathrm{SiO}_{2}$ is proposed. The charge exchange between slow states and silicon surface was investigated. A large difference in electron capturé and emission probabilities of local centers in $\mathrm{SiO}_{2}$ (polar medium) was observed. In graded insulator MIS structures a suppression of the hole field emission occurs. The experimental data on the Fowler-Nordheim emission of electrons enable calculating the tunneling parameter for such an MIS system. 


\section{REFERENCES}

11/ Iitovchenko, V.G. and Gorban, A.P., Physical Base of MIS, Naukova Dumkan, Kiev (1979).

/2/ Fischetti, M.V., J. App1. Phys. 57 (1985) 2860.

13/ Ricco, B. and Fischetti, M.V., J. Appl. Phys. 55 (1984) 4322; 57 (1985) 2854

14/ Evtuch, A.A., Litovhenko, V.G., and Popov, V.G., Ukr. Fiz. Zh. 32 (1987) 893.

15/ DiMaria, D.J., J. App1. Phys. 47 (1976) 4073.

16/ Arnett, P.C. and Yun, B.H., App1. Phys. Lett. 26 (1975) 24.

/7/ Lisovskii, I.P., Litovchenko, V.G., and Litvinov, R.O., Phys, Stat. So1. 53a (1979) 253.

18/ Breed, D. J., Solid St. Electron, 17 (1974) 1229.

19/ Litovchenko: V.G., Lisovskif, I.P., and Litvinov, R.0., Appl. Surf. Sci. 6 (1980) 15 .

/10/ Gale, R., Feigl, F.J., Magge, C.W., and Young, D.R., J. App1. Rhys, 54 (1983) 6938.

11/ Caplan, P.I., Poindexter, E.H., and Morrison, S.R., J. Appl. Phys. 53 (1982) 541.

112/ Kuchumov, B. M., Electron. Tekhn. I (1980) 94. 

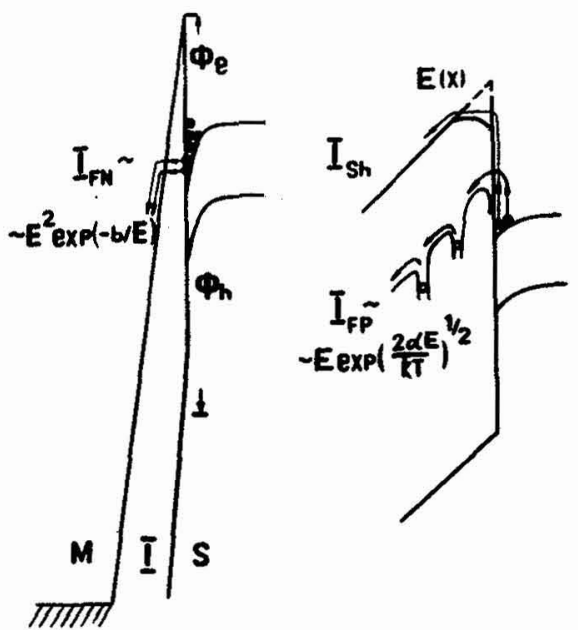

Fig. 1. The types of field emission of carriers in MIS structures.

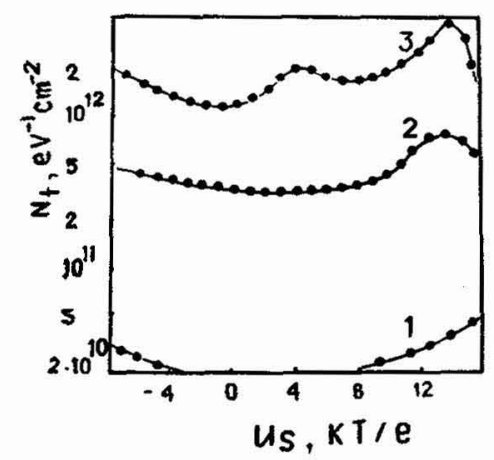

Fig. 3. The density of fast states as a function of surface potential with respect to center of the semiconductor and gap: (1) inftial MIS,

(2) UV - irradiated at $80 \mathrm{~K}$, and

(3) the same sample after field

treatment $\left(\mathrm{V}_{\mathrm{G}}=50 \mathrm{~V}, 30\right.$ hours $)$.

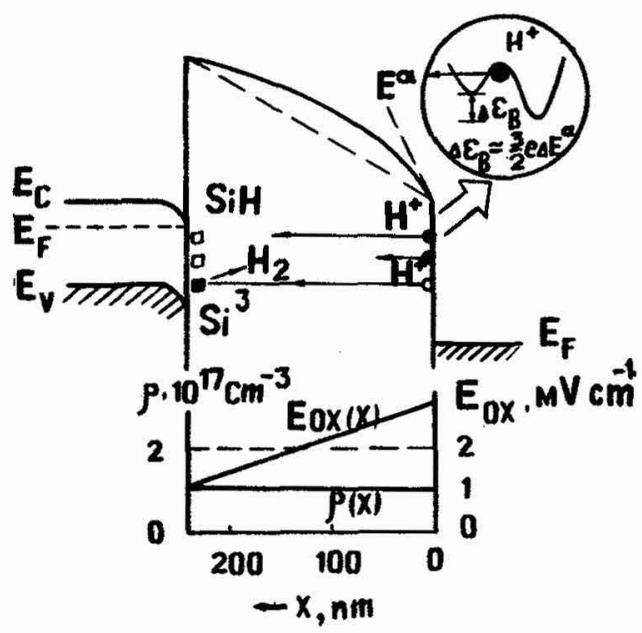

Fig. 2. The charge and field distribution in the modified oxide of an MIS structure (lower part) and the model of proton field emission and defect creation process caused by field treatment (upper part). In the insert, field induced lowering of the barrier $\left(\Delta \epsilon_{B}\right)$ necessary for the release of hydrogen is shown.

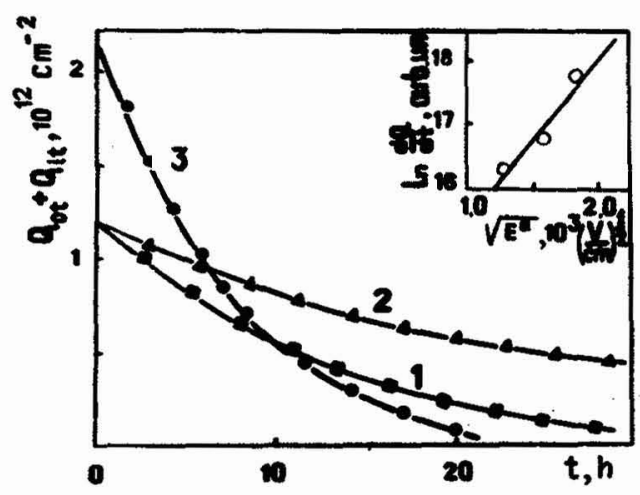

Fig. 4. The induced charge density (surface + bulk oxide) as a function of time after UV illumination and applied field, $(1,3) \mathrm{v}_{G}-50 \mathrm{v}$, and (2) $V_{G}-30 \mathrm{v}$. The structures were preliminary UV irradiated at $v_{G}-50 \mathrm{v}$, at $296 \mathrm{~K},(1,2)$ and (3) at $80 \mathrm{~K}$. In the insert, the rate of charging is shown in Poole-Frenkel coordinates. 

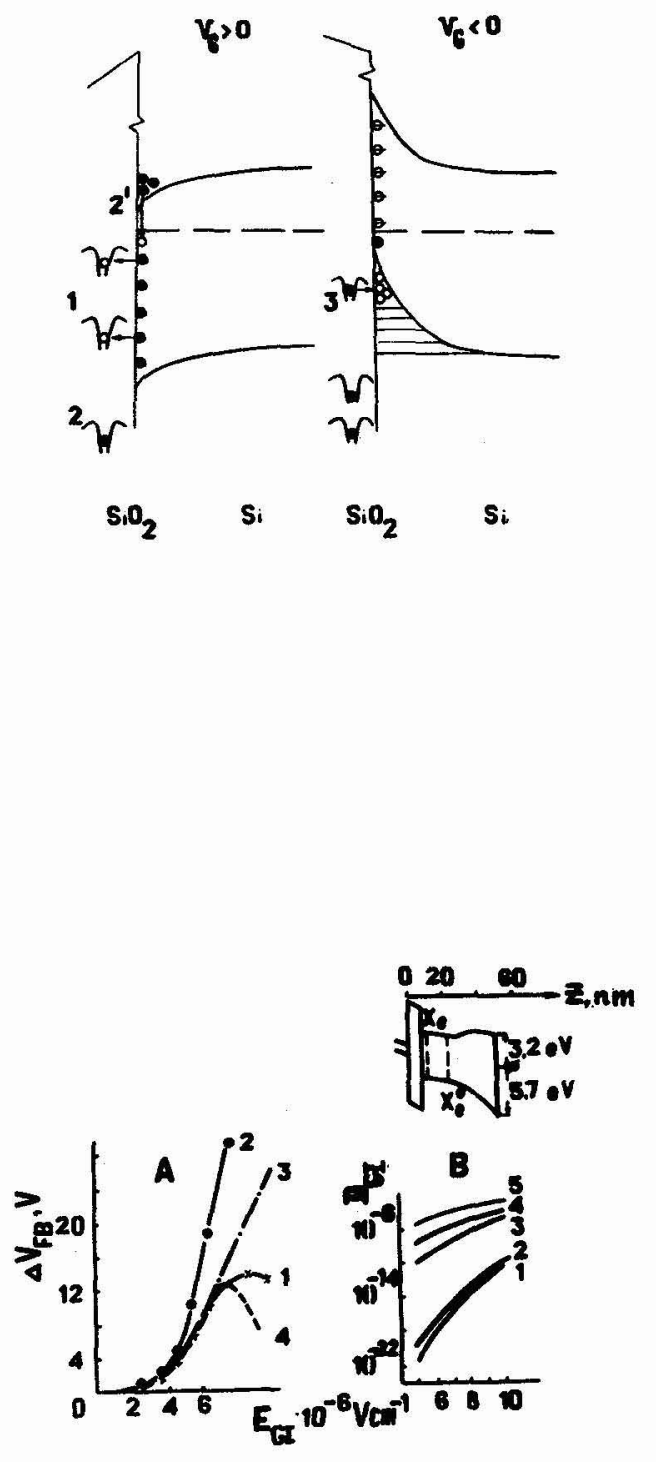

Fig. 5. The model of electron emission from $S i$ into slow states (at $V_{G}>0$ ) and back (at $v_{G}<0$ ), (1) The electron tunneling from the filled fast states onto any empty (positively charged) SS. (2) The level of an SS neutralized by electron trapping. (2') The filling with an electron of the emptied FS. (3) The electron tunneling from the part of neutral Ss into the inversion layer of silicon.

Fig. 6. High field emission characteristics of MIS structures.

(A) The field dependencies of $\Delta V_{F B}$ caused by carrier emission for:

(1) MNos; $v_{G}>0$,

(2) graded insulator MIS; $V_{G}>0$,

(3) curved 2 normalized to the thickness of $\mathrm{Si}_{3} \mathrm{~N}_{4}$ in $\mathrm{MNOS} ; \mathrm{V}_{\mathrm{G}}>0$,

(4) theoretically curve for graded insulator MIS; $\mathrm{V}_{\mathrm{G}}<0$.

(B) The field dependencies of the tunneling coefficient $D_{G I}$ for

(1) $\alpha=3.8 \times 10^{6} \mathrm{eV} / \mathrm{cm}$

(2) $\alpha=6.3 \times 10^{5} \mathrm{eV} / \mathrm{cm}$;

(3) $\alpha=0$;

(4) $\alpha=-6.7 \times 10^{5} \mathrm{eV} / \mathrm{cm}$;

(5) $\alpha=-4 \times 10^{6} \mathrm{eV} / \mathrm{cm}$. 